\title{
Theoretical investigations into heat transfer in laser-welded steel sheets
}

\author{
Wiesława Piekarska • Marcin Kubiak
}

CEEC-TAC1 Conference Special Issue

(C) The Author(s) 2012. This article is published with open access at Springerlink.com

\begin{abstract}
This study contains mathematical modelling and numerical analysis of heat transfer in laser beam welding process. The temperature field was obtained on the basis of numerical solution into unsteady heat transfer equation with convective term and volumetric heat sources taken into account. Volumetric heat source model describing laser beam power distribution in combined truncated cone-cylinder volume was developed. Due to the wide range of temperatures appearing in the process latent heat of fusion, evaporation as well as latent heat of phase transformations in solid state were taken into account in the solution algorithm. On the basis of developed numerical algorithms an analysis of heat transfer in laser butt-welded steel sheets as a three-dimensional initial-boundary problem was performed.
\end{abstract}

Keywords Laser welding - Heat transfer - Phase transformations · Latent heat · Numerical modelling

\section{Introduction}

Laser beam welding has increasing application in many industries. This welding method allows joining materials previously regarded as a non-weldable or difficulty weldable [1-4]. Because of technological advantages, this technology successfully displaces conventional welding methods in many applications. However, laser welding of steel is accompanied by many phenomena not found in

\section{W. Piekarska $\cdot$ M. Kubiak $(\bowtie)$}

Institute of Mechanics and Machine Design Foundations, Czestochowa University of Technology, Dabrowskiego 73,

42-200 Czestochowa, Poland

e-mail: kubiak@imipkm.pcz.pl conventional welding [2]. Absorbed laser light vaporise material and forms a 'keyhole' that contains ionised vapour. The laser power is absorbed in the ionised vapour and transferred to the walls of the 'keyhole' forming the weld pool [3-5]. Moreover, the interaction of concentrated heat source on the material is responsible for generating high temperature gradients and high cooling rates appearing in the joint. This leads to occurring of hardening structures in the weld and heat-affected zone (HAZ) even in susceptible to welding, unalloyed and low-alloy constructional steels [6]. The quality of the joint is determined by process parameters such as: laser mode, beam radius, laser power and welding speed. Therefore, the knowledge about temperature profile of laser welded joints allows for a prediction of these parameters in terms of size and shape of the weld [7-9].

Theoretical analysis of laser-material interaction is very complex and includes various physical phenomena such as evaporation, melting, solidification, microstructure transformation, thermal and structural stress etc. [10-16]. Mathematical and numerical models usually describe chosen phenomena, due to the computational complexity of the problem. Therefore, coupled thermal phenomena and phase transformations in solid state are usually ignored in numerical analysis of welding processes [5, 8, 9, 15, 16]. However, latent heat generated during phase transformations in heat treatment of steel influences temperature distribution and has a significant effect on numerically predicted microstructure composition [17, 18].

A very important issue in modelling of laser beam welding is an appropriate selection of heat source power distribution which is primarily responsible for the melted pool shape and temperature distribution in the joint. Researchers are constantly looking for new mathematical models describing the distribution of the energy flux 
(taking into account the real process conditions) through theoretical study on laser induced plasma formation [1921] or assuming Gaussian-like simplified volumetric heat source model $[5,7,13]$ with decreasing energy intensity in material penetration direction, especially when developed theoretical model requires consideration of entire 3D workpiece geometry during calculations. A major problem in developing of simplified models is the determination of the size and shape of the heat source along the thickness of the workpiece corresponding to the experimental data with appropriate accuracy. Therefore, it is difficult to define a universal heat source model. From the analysis of laser beam welding process it is observed that heat source power decreases with increasing depth of penetration. Furthermore, obtained weld shape in deep penetration welding is often a mushroom-shape, mainly depending on the welding speed $[4,8]$.

In this study, theoretical model is presented to analyse coupled thermal phenomena and phase transformations in solid state during laser butt-welding of steel. Temperature field is calculated on the basis of numerical solution into heat transfer equation in Eulerian coordinates using finite difference method in forward Euler's time integration scheme. A heat source model is developed for the laser beam deep penetration welding, allowing better approximation of heat transfer in welded workpiece. Latent heat associated with material's state change and latent heat generated during phase transformations in solid state are taken into account in solution algorithms. Dilatometric research of S460 steel is performed to determine continuous-cooling-transformation diagram (CCT) and final fractions of structure constituents used in the model. Results of calculations are verified by the experiment. It is shown that the effect of latent heat associated with microstructure changes on temperature history in laser welding is considerable and should not be neglected in theoretical models.

Finally, it is demonstrated that developed heat source model gives a good approximation of fusion zone and HAZ geometry for mushroom-shape welds and well agrees with experimental result.

\section{Theoretical model}

Temperature distribution in butt-welding is determined by process parameters, mainly distribution of laser beam power and welding speed. Phase transformations due to melting, solidification and evaporation as well as phase transformations in solid state are taken into account in theoretical investigations. At boundaries of the workpiece heat loss due to convection, radiation and evaporation is assumed. Sketch of considered system is illustrated in Fig. 1.

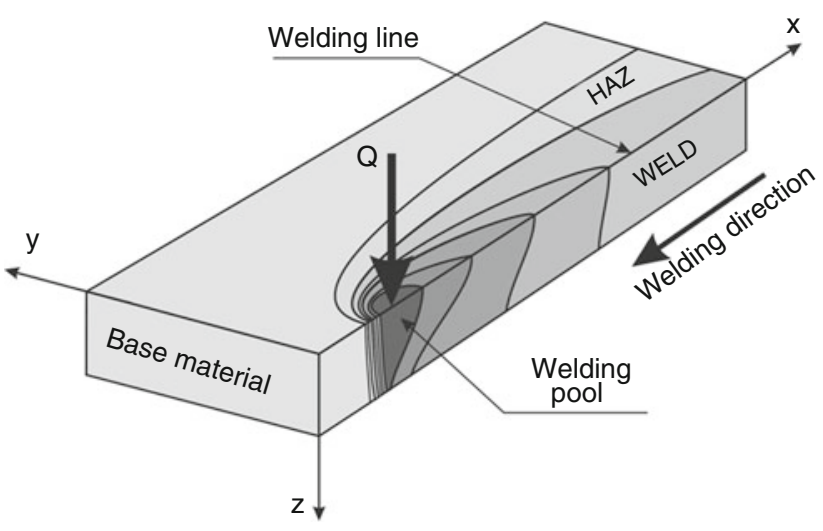

Fig. 1 Schematic sketch of laser beam welding

Heat transfer

Heat transfer in welded joint is described by transient heat transfer equation with convective term

$\nabla \cdot(\lambda \nabla T)=C_{\mathrm{ef}}\left(\frac{\partial T}{\partial t}+\nabla T \cdot \mathbf{v}\right)-\tilde{Q}$

where $\lambda=\lambda(T)$ is thermal conductivity dependent on temperature, $C_{\text {ef }}$ is effective heat capacity, $\tilde{Q}$ is a volumetric heat source and $\mathbf{v}=\mathbf{v}(\mathrm{x}, \mathrm{y}, \mathrm{z}, t)$ is a vector determined by welding speed, $T(\mathrm{x}, \mathrm{y}, \mathrm{z}, t)$ is a temperature and $t$ is time.

Equation (1) is completed by initial condition $t=0$ : $T=T_{0}$ and boundary conditions of Dirichlet, Neumann and Newton type, taking into account a heat loss due to convection and radiation [15]

$-\lambda \frac{\partial T}{\partial n}=-q+\alpha\left(\left.T\right|_{\Gamma}-T_{0}\right)+\varepsilon \sigma\left(T^{4}-T_{0}^{4}\right)$

where $\alpha$ is a convective coefficient, $\varepsilon$ is radiation coefficient, $\sigma$ is Stefan-Boltzmann constant and $q=q(r, 0)$ is the heat flux towards the top surface of welded workpiece $(z=0)$ in the source activity zone.

Thermal conductivity coefficient changing with temperature is assumed in theoretical model (Fig. 2). In solid state $\lambda=\lambda(T)$ is defined according to data form the literature [22]. Much higher value of $\lambda(T)$ is assumed at high temperatures, which corresponds to the motion of liquid material in the welding pool.

Laser beam heat source

In this study, gaussian heat source power distribution is developed for mushroom-shape welds (obtained during experiment). At the deep of penetration $\alpha_{z} d$ heat source power is decreasing in a shape of a truncated cone. Remaining laser power distribution is constant in a shape 


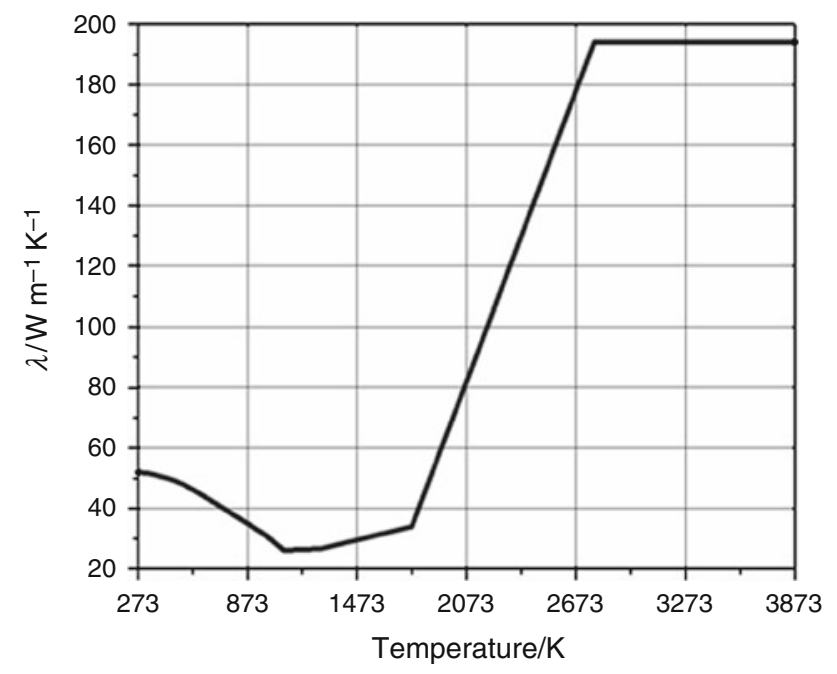

Fig. 2 Thermal conductivity assumed in theoretical model

of a cylinder. Heat source power distribution in truncated cone volume is expressed as follows [13]:

$Q(r, z)=\frac{\eta Q_{\mathrm{L}}}{V} \exp \left[\left(1-\frac{r^{2}}{r_{\mathrm{z}}^{2}}\right)\left(1-\frac{z}{d}\right)\right]$

where $Q_{\mathrm{L}}$ is a laser beam power, $\eta$ is efficiency, $d$ is a total penetration depth, $r=\sqrt{x^{2}+y^{2}}$ is a current beam radius and $z \in\left[0 ; \alpha_{z} d\right]$ is a current penetration, $V$ is a volume of the heat source.

Radius $r_{\mathrm{z}}$ is a total laser beam radius along penetration direction, defined as:

$r_{\mathrm{z}}=r(z)=r_{0}-\left(r_{0}-r_{\alpha \mathrm{z}}\right) \frac{z}{\alpha_{\mathrm{z}} d}$

where $r_{0}$ is a radius of laser beam spot at the top surface of the workpiece $(z=0)$ and $r_{\alpha z}$ is a radius of the beam at the deep of penetration $z=\alpha_{z} d, \alpha_{z} \in[0 ; 1]$ is experimentally defined coefficient depending on the welding speed.

Volume of the heat source consists of truncated cone and cylinder (Fig. 3) and is expressed by the following equation:

$V=\pi d\left(r_{\alpha \mathrm{z}}^{2}\left(1-\frac{2}{3} \alpha_{\mathrm{z}}\right)+\frac{1}{3} \alpha_{\mathrm{z}}\left(r_{0}^{2}+r_{0} r_{\alpha \mathrm{z}}\right)\right)$

Phase transformations

Solid-liquid transformation in welded steel is assumed with fuzzy solidification front between solidus $\left(T_{\mathrm{S}}\right)$ and liquidus $\left(T_{\mathrm{L}}\right)$ temperatures. Latent heat of fusion is defined in a body flux [23]

$\tilde{Q}^{\mathrm{SL}}=\rho_{\mathrm{S}} H_{\mathrm{L}} \frac{d f_{\mathrm{s}}(T)}{d T} \dot{T}$

where $\rho_{\mathrm{S}}$ is solidus density, $H_{\mathrm{L}}$ is a latent heat of fusion and $f_{s}(T) \in[0 ; 1]$ is a function determining the fraction of solid phase in the mushy zone.

After including a body flux (6) into heat transfer equation (1) and assuming linear approximation of solid fraction in the mushy zone, latent heat of fusion is considered in the effective heat capacity, according to the following relation:

$C_{\mathrm{ef}}^{\mathrm{SL}}(T)= \begin{cases}\rho_{\mathrm{S}} c_{\mathrm{S}} & \text { for } T<T_{\mathrm{S}} \\ \rho_{\mathrm{SL}} c_{\mathrm{SL}}+\frac{\rho_{\mathrm{S}} H_{\mathrm{L}}}{T_{\mathrm{L}}-T_{\mathrm{S}}} & \text { for } T \in\left[T_{\mathrm{S}} ; T_{\mathrm{L}}\right] \\ \rho_{\mathrm{L}} c_{\mathrm{L}} & \text { for } T>T_{\mathrm{L}}\end{cases}$

where subscripts $\mathrm{S}$ and $\mathrm{L}$ stand for solid and liquid phase respectively, $c$ is a specific heat. The product of density and specific heat in the mushy zone depends linearly on solid fraction $\rho_{\mathrm{SL}} c_{\mathrm{SL}}=\rho_{\mathrm{S}} c_{\mathrm{S}} f_{\mathrm{S}}+\rho_{\mathrm{L}} c_{\mathrm{L}}\left(1-f_{\mathrm{S}}\right)$.

Similarly during liquid-gas transformation, latent heat of evaporation in temperatures exceeding boiling point $\left(T_{\mathrm{b}}\right)$
Fig. 3 Laser beam heat source power distribution a at the top and bottom surfaces of the joint and $\mathbf{b}$ in cross-section of the joint. Heat source parameters are: $Q_{\mathrm{L}}=3,800 \mathrm{~W}, \eta=75 \%$, $r_{0}=1 \mathrm{~mm}, r_{\alpha \mathrm{z}}=0.4 \mathrm{~mm}$, $\alpha_{\mathrm{z}}=0.5$

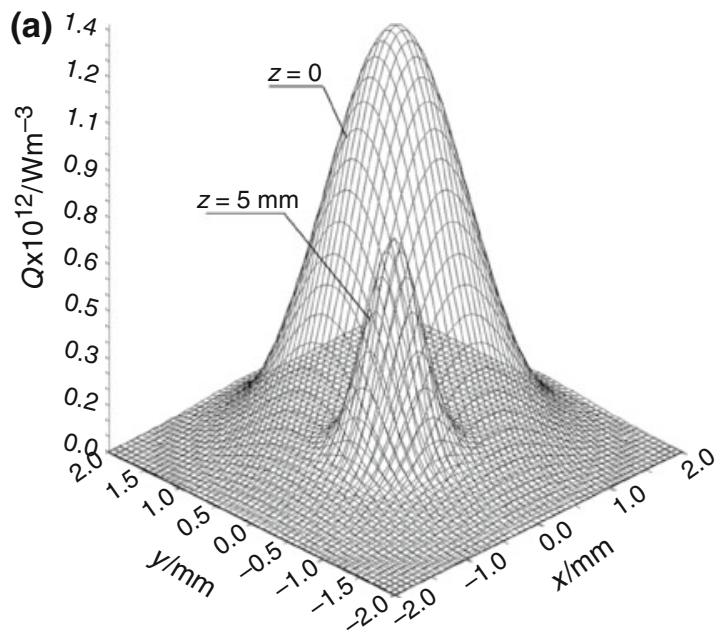

(b)

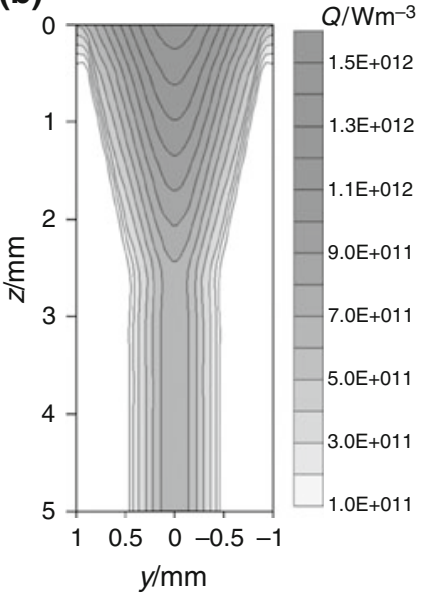


of steel is considered in the capacity model. Heat source $\tilde{Q}^{\mathrm{b}}$ derived from the evaporation is included into equation (1). After assuming linear approximation of liquid fraction $f_{1} \in$ $[0 ; 1]$ between boiling point and maximum temperature $\left(T_{\max }\right)$ and a full equilibrium of metal vapour pressure in the keyhole and pressure of shielding gases, effective heat capacity in temperatures exceeding boiling point is defined as follows [15]:

$C_{\mathrm{ef}}^{\mathrm{b}}(T)=\rho_{\mathrm{L}} c_{\mathrm{L}}+\frac{\rho_{\mathrm{L}} H_{\mathrm{b}}}{T_{\max }-T_{\mathrm{b}}}$ for $T \geq T_{\mathrm{b}}$

where $H_{\mathrm{b}}$ is a latent heat of evaporation.

Generated heats during transformation of austenite into ferrite, pearlite, bainite and martensite in cooling process [24] are included into effective heat capacity.

$C_{\mathrm{ef}}^{\mathrm{ph}}(T)=\left\{\begin{array}{cl}\rho_{\mathrm{S}} c_{\mathrm{S}}+\sum_{\mathrm{i}} \rho_{\mathrm{S}} H_{\mathrm{i}}^{\eta_{\mathrm{i}} \frac{d \eta_{\mathrm{i}}(T)}{d T}} & \text { for } T \in\left[T_{\mathrm{s}}^{\mathrm{i}} ; T_{\mathrm{f}}^{\mathrm{i}}\right] \\ \rho_{\mathrm{S}} c_{\mathrm{S}} & \text { for } T \notin\left(T_{\mathrm{s}}^{\mathrm{i}} ; T_{\mathrm{f}}^{\mathrm{i}}\right)\end{array}\right.$

where $T_{\mathrm{s}}^{\mathrm{i}}$ and $T_{\mathrm{f}}^{\mathrm{i}}$ are start and final temperatures of each phase transformation, $H_{\mathrm{i}}^{\eta_{\mathrm{i}}}$ is a latent heat of $i$-th phase transformation, $\eta_{i}$ is a volumetric fraction of $i$-th structural constituent.

Latent heat of austenite transformation into ferrite $\left(H_{\mathrm{A} \rightarrow \mathrm{F}}\right)$, pearlite $\left(H_{\mathrm{A} \rightarrow \mathrm{P}}\right)$, bainite $\left(H_{\mathrm{A} \rightarrow \mathrm{B}}\right)$ and martensite $\left(H_{\mathrm{A} \rightarrow \mathrm{M}}\right)$ as well as heat capacity of structural constituents of steel are determined by experimental research $[25,26]$ for appropriate temperatures of transformations, whereas volumetric fraction $\eta_{i}$ results from the kinetics of phase transformation. A fraction $\eta_{i}$ for diffusive phase transformations (austenite into ferrite, pearlite and bainite) is determined by Johnson-Mehl-Avrami (JMA) equation [24, 27, 28]

$\eta_{(\cdot)}(T, t)=\eta_{(\cdot)}^{\%}\left(1-\exp \left(-b(t(T))^{\mathrm{n}}\right)\right), \quad \eta_{A}=1-\sum_{\mathrm{k}=1}^{4} \eta_{\mathrm{k}}$

where $\eta_{(\cdot)}^{\%}$ is the final fraction for determined cooling rate, estimated basing on microstructure analysis of examined steel, $\eta_{A}$ is austenite fraction.

Coefficients $b=b(T)$ and $n=n(T)$ are determined by start $\left(\eta_{\mathrm{s}}=0.01\right)$ and final $\left(\eta_{\mathrm{f}}=0.99\right)$ conditions for phase transformation as well as start and final times of phase transformation $\left(t_{\mathrm{s}}\right.$ and $\left.t_{\mathrm{f}}\right)$ estimated using CCT diagram [29] for welded steel

$$
b(T)=-\frac{\ln \left(\eta_{\mathrm{f}}\right)}{\left(t_{\mathrm{s}}\right)^{n(\mathrm{~T})}}, \quad n(T)=\frac{\ln \left(\ln \left(\eta_{\mathrm{f}}\right) / \ln \left(\eta_{\mathrm{s}}\right)\right)}{\ln \left(t_{\mathrm{s}} / t_{\mathrm{f}}\right)}
$$

where $t$ is a time.

Volumetric fraction of martensite $(\eta M)$ is estimated using Koistinen-Marburger (KM) equation

$\eta_{\mathrm{M}}(T)=\eta_{(\cdot)}^{\%}\left(1-\exp \left(-k\left(M_{\mathrm{s}}-T\right)\right)\right), \quad T \in\left[M_{\mathrm{s},} M_{\mathrm{f}}\right]$
Coefficient $k$ depends on martensite phase start and final temperatures ( $M_{\mathrm{s}}$ and $M_{\mathrm{f}}$ ) determined also basing on CCT diagram

$k=-\frac{\ln \left(\eta_{\mathrm{S}}\right)}{M_{\mathrm{s}}-M_{\mathrm{f}}}=-\frac{\ln (0.01)}{M_{\mathrm{s}}-M_{\mathrm{f}}}$

\section{Results and discussion}

The mathematical model of thermal phenomena accompanying welding processes was implemented into the computer solver. Governing equation (1) was numerically solved using finite difference method in forward Euler's time integration scheme. For the stabilization of solution algorithms Péclet number was implemented directly into central difference quotients. Numerical analysis of laser but-welding without additional material is performed as a three-dimensional problem (Fig. 4) assuming perfect contact between joined sheets. Analyzed domain with dimensions: $L=250 \mathrm{~mm}, \quad a=50 \mathrm{~mm}$ and $g=5 \mathrm{~mm}$ is considered as a half of the joint to the plane of symmetry and discretized by differential grid with constant spatial step $0.01 \mathrm{~mm}$ in $x$ direction and linearly decreasing spatial step in $y$ direction (Fig. 4b) from $0.05 \mathrm{~mm}$ in the heat source activity zone, where large temperature gradients are present, up to $2 \mathrm{~mm}$ in lower temperatures. The average time of calculations for $25 \mathrm{~s}$ of welding simulation lasted about $16 \mathrm{~h}$. Calculations were performed on PC with Quad Core $2.40 \mathrm{GHz}$.

Illustrated in Fig. 3 heat source power distribution and welding speed $v=0.7 \mathrm{~m} \mathrm{~min}^{-1}$ are used in calculations. The analysis is carried out for sheets made of S460 steel with chemical composition: $0.19 \mathrm{C}, 1.62 \mathrm{Mn}, 0.6 \mathrm{Si}$,

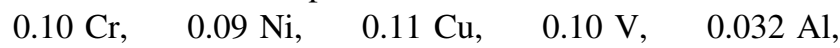
$0.012 \mathrm{Nb}$ (wt\%). Thermo-physical properties used in calculations are summarized in Table 1.

Used in the analysis CCT diagram of S460 steel and final fractions of structure constituents were obtained on the basis of dilatometric research performed at Institute for Ferrous Metallurgy in Gliwice (Poland) using dilatometer DIL805 produced by Bähr Thermoanalyse $\mathrm{GmbH}$, equipped with a LVDT measuring head, with a theoretical resolution of $0.057 \mu \mathrm{m}$. In dilatometric analysis a constant austenitization temperature $T_{A}=1,200{ }^{\circ} \mathrm{C}$ was assumed and different heating and cooling rates, simulating thermal cycles in welding. The microstructure of analyzed samples was afterwards evaluated by microstructure analysis, supported by measurements of microhardness. Obtained CCT diagram with final fractions of structure constituents is illustrated in Fig. 5.

Figure 6 shows temperature distribution for chosen points at the top surface of the joint $(z=0)$ and in a distance $y=1 \mathrm{~mm}$ from the centre of laser beam heat 


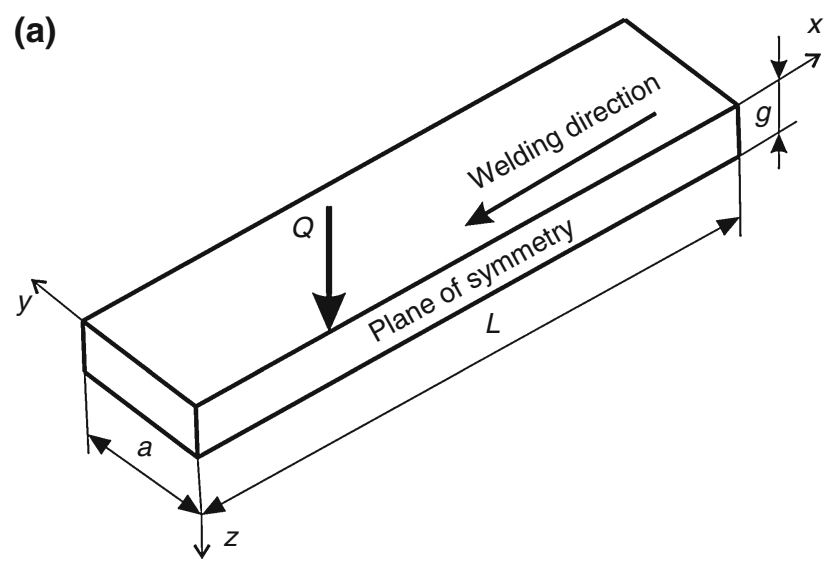

(b)

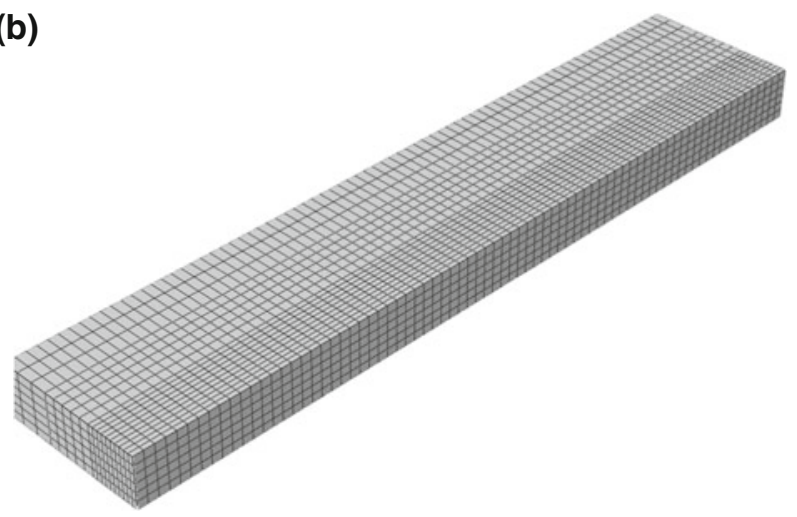

Fig. 4 Sketch of $\mathbf{a}$ analysed initial-boundary problem and $\mathbf{b}$ finite difference mesh used in calculations

source. Solidus, liquidus and boiling temperatures are marked as well as temperature range $\left[800^{\circ} \mathrm{C} ; 500{ }^{\circ} \mathrm{C}\right]$, where cooling rates are determined for analysis of phase transformations in solid state. It can be observed that maximum temperatures are obtained in the centre of heat source activity zone. At this point temperature exceeds the boiling point of steel $\left(T_{b}=3,010 \mathrm{~K}\right)$, leading to the evaporation and creation of the keyhole. If maximum temperature exceeds solidus temperature $\left(T_{\mathrm{S}}\right)$ material is melted. Complete melting is achieved when temperature reaches liquidus temperature $\left(T_{\mathrm{L}}\right)$. When maximum temperature exceeds austenitization temperature $\left(T_{\mathrm{g}}\right)$, the material is in the zone of structural transformations (HAZ). Below austenitization temperature welded material is treated as untransformed base material.

Effective heat capacity in solid state for chosen points at the top surface of the joint is shown in Fig. 7. It can be noticed that various effective heat capacity is obtained depending on the kinetics of phase transformations in solid state and different start and final temperatures determined for each cooling rate in the weld and HAZ. It can be observed that for presented in Fig. 7 material points the effective heat capacity is
Table 1 Thermo-physical properties assumed in computer simulations

\begin{tabular}{lll}
\hline Thermo-physical property & & Value \\
\hline Solidus temperature & $T_{\mathrm{S}} / \mathrm{K}$ & 1,750 \\
Liquidus temperature & $T_{\mathrm{L}} / \mathrm{K}$ & 1,800 \\
Boiling point & $T_{\mathrm{b}} / \mathrm{K}$ & 3,010 \\
Ambient temperature & $T_{0} / \mathrm{K}$ & 293 \\
Specific heat of solid phase & $c_{\mathrm{S}} / \mathrm{J} \mathrm{kg}^{-1} \mathrm{~K}^{-1}$ & 650 \\
Specific heat of liquid phase & $c_{\mathrm{L}} / \mathrm{J} \mathrm{kg}^{-1} \mathrm{~K}^{-1}$ & 840 \\
Density of solid phase & $\rho_{\mathrm{S}} / \mathrm{kg} \mathrm{m}^{-3}$ & 7,800 \\
Density of liquid phase & $\rho_{\mathrm{L}} / \mathrm{kg} \mathrm{m}^{-3}$ & 6,800 \\
Latent heat of fusion & $H_{\mathrm{L}} / \mathrm{J} \mathrm{kg}^{-1}$ & $270 \times 10^{3}$ \\
Latent heat of evaporation & $H_{\mathrm{b}} / \mathrm{J} \mathrm{kg}^{-1}$ & $76 \times 10^{5}$ \\
Latent heat of phase & $H_{A \rightarrow F} / \mathrm{J} \mathrm{kg}^{-1}$ & $8 \times 10^{4}$ \\
transformations & $H_{A \rightarrow P} / \mathrm{J} \mathrm{kg}^{-1}$ & $9 \times 10^{4}$ \\
& $H_{A \rightarrow B}=H_{A \rightarrow M} /$ & $11.5 \times 10^{4}$ \\
& $\mathrm{~J} \mathrm{~kg}$ & \\
Convective heat transfer & $\alpha / \mathrm{W} \mathrm{m}{ }^{-2} \mathrm{~K}^{-1}$ & 50 \\
coefficient & & \\
Boltzmann's constant & $\sigma / \mathrm{W} \mathrm{m}{ }^{-2} \mathrm{~K}^{-4}$ & $5.67 \times 10^{-8}$ \\
Surface radiation emissivity & $\varepsilon$ & 0.5 \\
\hline
\end{tabular}
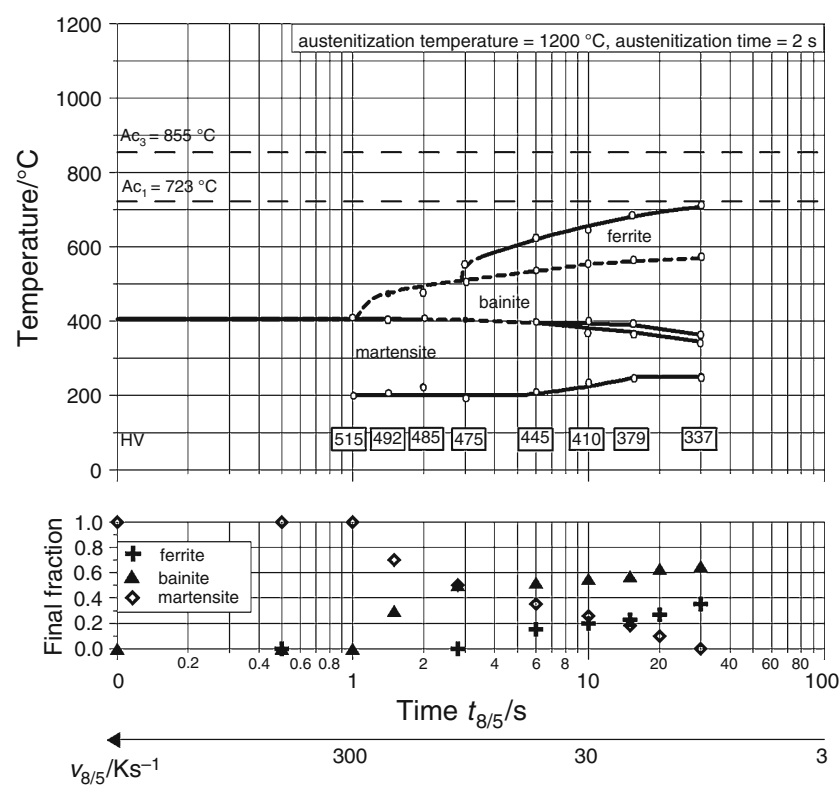

Fig. 5 CCT diagram of S460 steel and final fractions of microstructure constituents

determined by bainite and martensite transformation. Fig. 8 shows temperature history of a point on the top surface of the joint at a distance $1 \mathrm{~mm}$ from the weld line. The solid line represents temperature distribution affected by latent heat included into the model, whereas dotted line represents temperature distribution calculated 

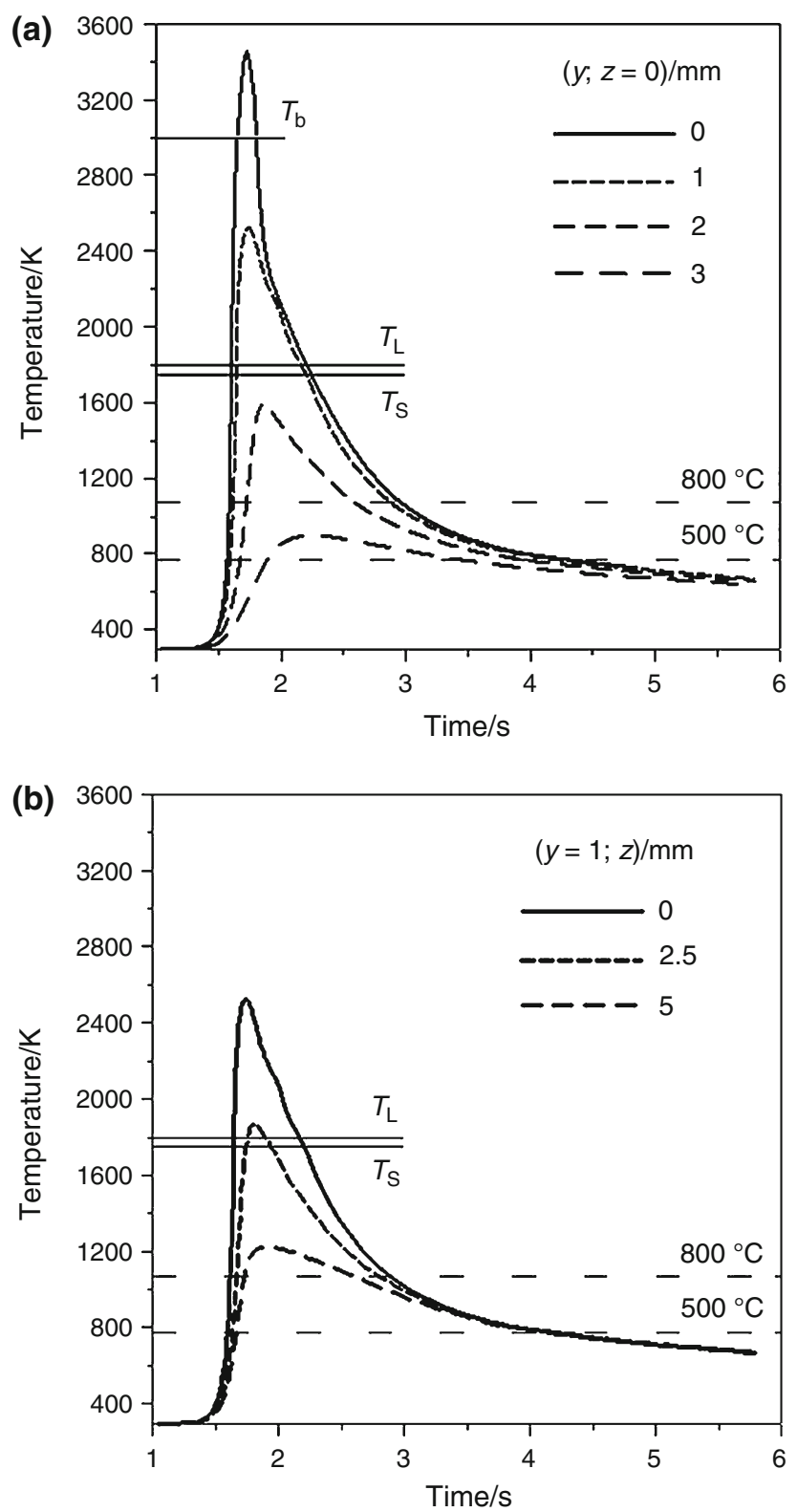

Fig. 6 Temperature distribution for chosen points: a at the top surface of the weld and $\mathbf{b}$ along direction of material penetration, in a distance $y=1 \mathrm{~mm}$ from the centre of laser beam heat source

without the effect of latent heat (latent heat of phase transformations in solid state was omitted in the model). It is observed that the impact of latent heat of phase transformations in solid state on temperature distribution is measurable.

Figure 9 illustrates temperature field at the top surface of the workpiece (from the face of the weld). The welding pool boundary is represented by a black solid line (solidus isotherm), whereas dashed line defines heat affected zone boundary (austenitization temperature $T_{\mathrm{g}}=1,000 \mathrm{~K}$ ).

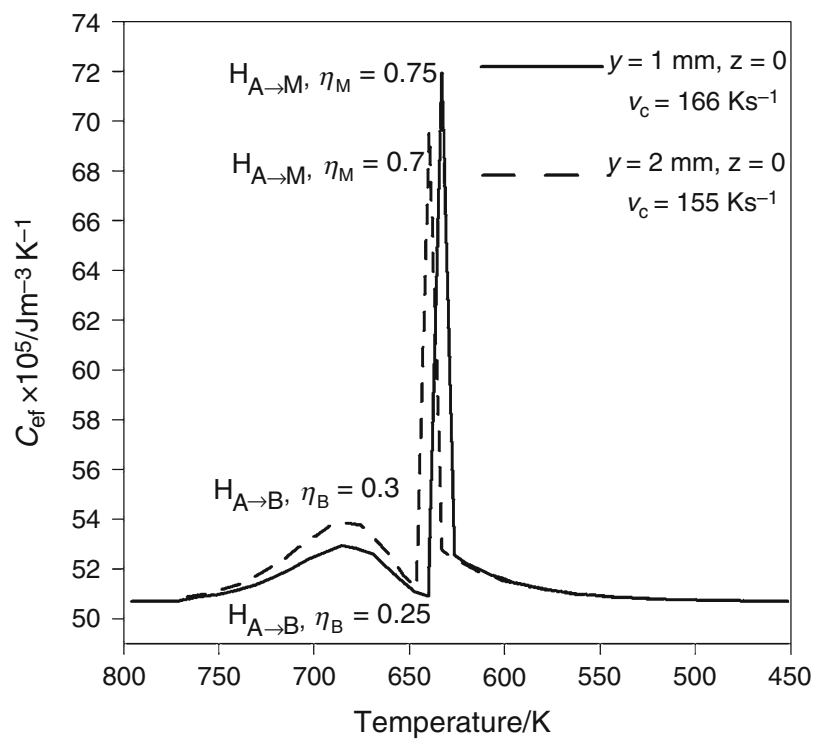

Fig. 7 Effective heat capacity for kinetics of phase transformations calculated for two chosen thermal cycles

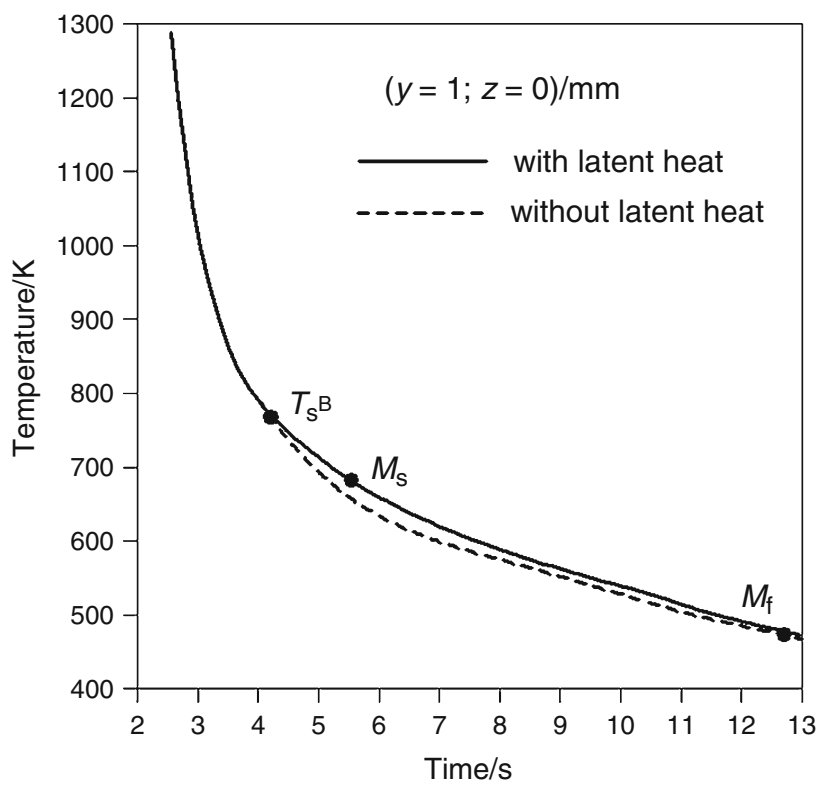

Fig. 8 Temperature history in a chosen point of the joint showing the influence of latent heat

The formation of laser butt-welded joint is presented in Fig. 10. This figure illustrates temperature distribution at different analysis time. At time $t=1.72 \mathrm{~s}$ maximum temperatures are achieved in the joint. For $t=1.85 \mathrm{~s}$ maximum size of melted zone is achieved at the top surface of the joint $(z=0)$. Maximum size of heat affected zone is reached at time $t=2.47 \mathrm{~s}$. 


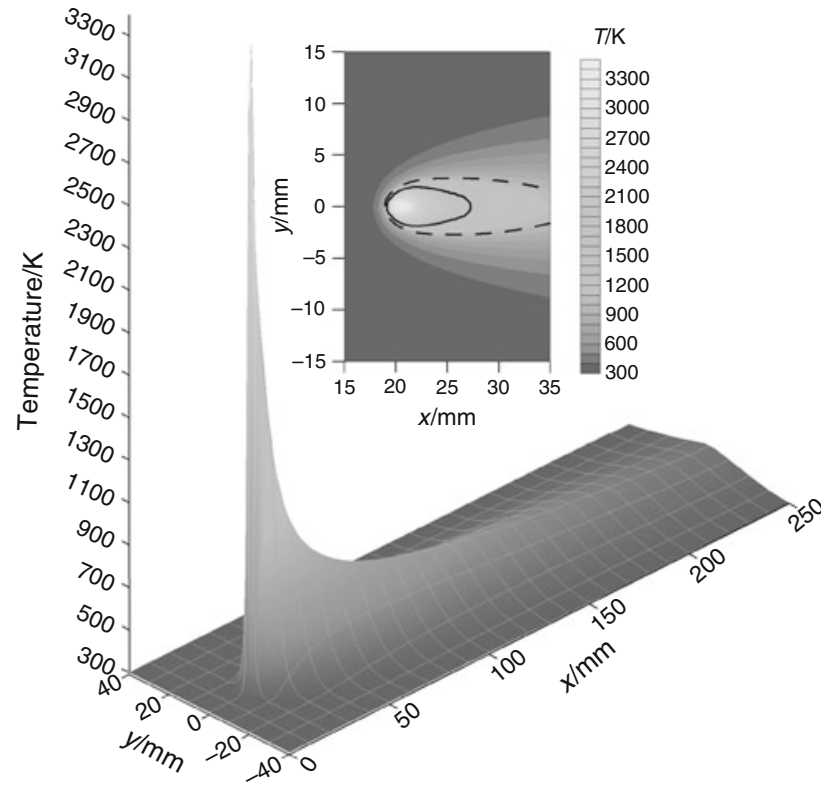

Fig. 9 Temperature field at the top surface of the joint $(z=0$, form the face of the weld)

In order to verify the correctness of elaborated models, $\mathrm{CO}_{2}$ laser welding experiment was performed at Welding Institute in Gliwice. TRUMPH Lasercell 1005 with $\mathrm{CO}_{2}$

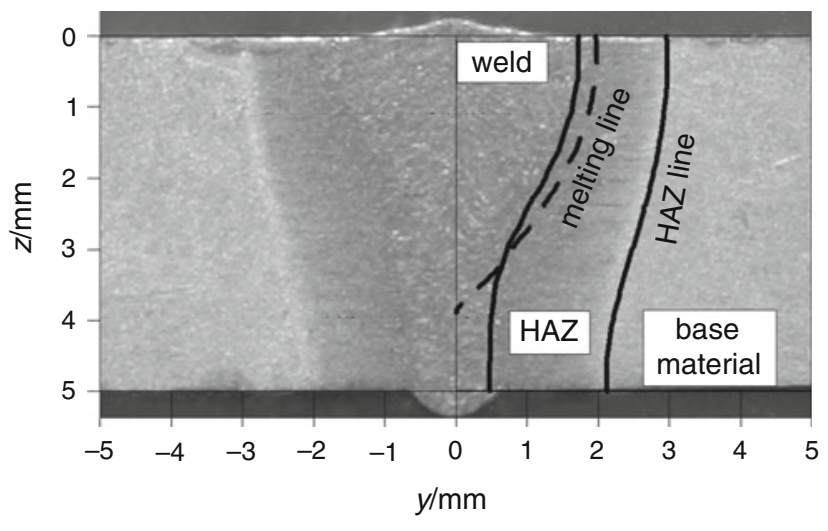

Fig. 11 Comparison of numerically predicted melted zone and HAZ geometry with weld obtained in the experiment

laser generator $\left(Q_{\mathrm{L}}=3,800 \mathrm{~W}\right)$ was used in the experiment. Sheets made of S460 steel with dimensions: $250 \times 50 \times 5 \mathrm{~mm}$ were arranged along the longest side without a gap (perfect contact). Welding speed was set to $0.7 \mathrm{~m} \mathrm{~min}^{-1}$.

Figure 11 shows the comparison of experimentally obtained weld with numerically estimated melted zone and heat affected zone geometries. As shown in this figure, the calculated geometry of the weld and HAZ agrees well with the experimental result.
Fig. 10 Temperature distribution in the cross-section of the weld for different simulation times
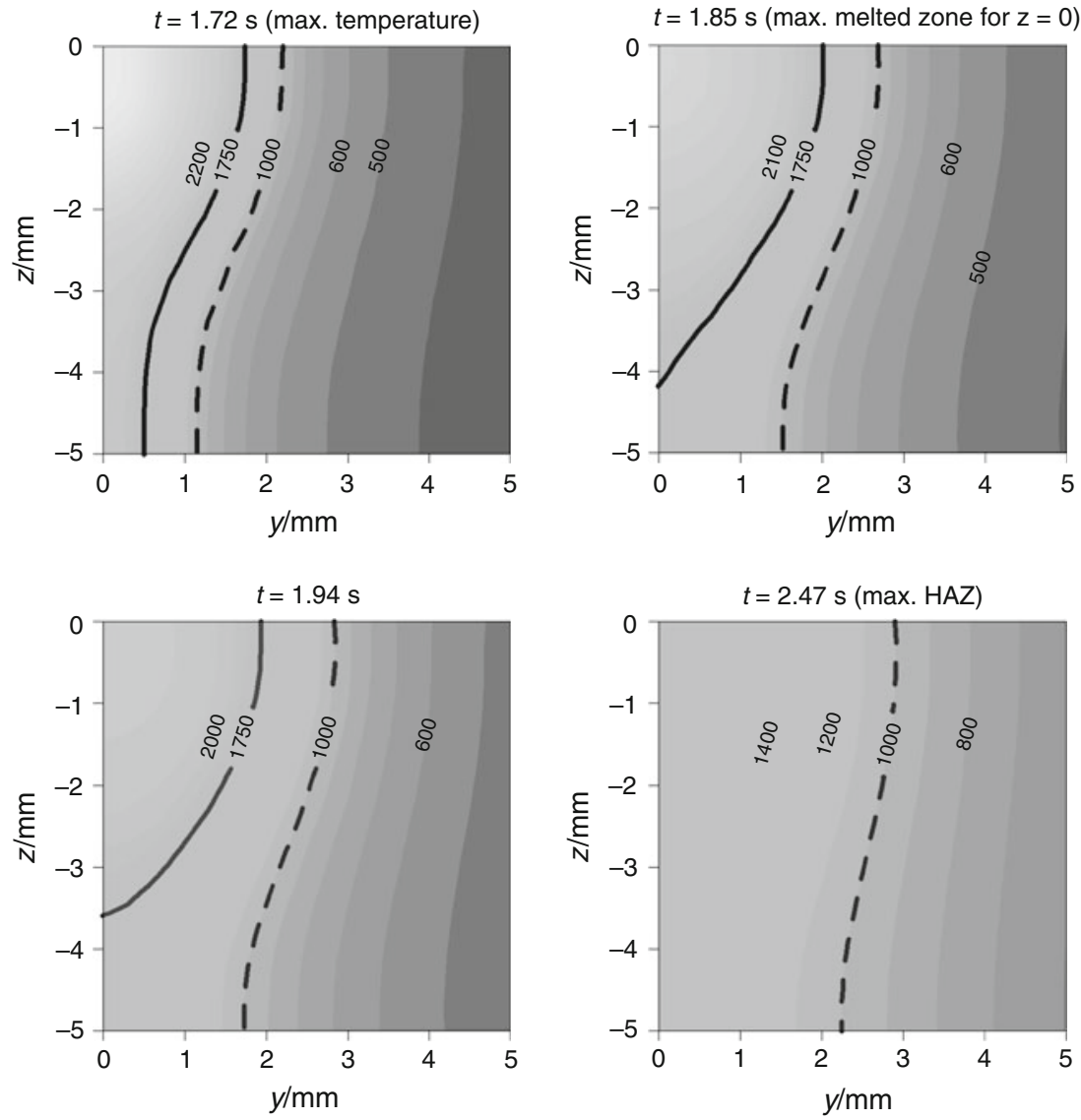


\section{Conclusions}

Three-dimensional unsteady heat transfer numerical model was developed for numerical analysis of temperature field in laser-welded sheets made of S460 steel. Volumetric heat source model was developed for a determination of laser beam power distribution in deep penetration welding. Latent heat associated with microstructure changes was included into the model. On the basis of calculated temperature field melted zone and HAZ geometry was determined. The following conclusions can be made from this study:

1. Estimated geometry of the weld and HAZ is very close to this obtained in the experiment, thus developed heat source model allows for a better approximation of temperature field in laser welded joints.

2. Theoretical model can be used not only for a prediction of joint geometry but also to analyze influence of process parameters on the size and shape of laser welded joints.

3. Heat generated during phase transformations in solid state included into theoretical model allows for a better approximation of temperature distribution in welded joint.

Open Access This article is distributed under the terms of the Creative Commons Attribution License which permits any use, distribution, and reproduction in any medium, provided the original author(s) and the source are credited.

\section{References}

1. Steen WM. Laser material processing. London: Springer; 1991.

2. Dawes C. Laser welding. New York: Abington Publishing; 1992.

3. Jin X, Li L, Zhang Y. A study of fresnel absorption and reflections in the keyhole in deep penetration laser welding. J Phys D. 2002;35:2304-10.

4. Pilarczyk J, Banasik M, Dworak J, Stano S. Technological applications of laser beam welding and cutting at the Instytut Spawalnictwa. Przeglad Spawalnictwa. 2006;5-6:6-10.

5. Han L, Liou FW. Numerical investigation of the influence of laser beam mode on melt pool. Int J Heat Mass Transf. 2004; 47:4385-402.

6. Bokota A, Piekarska W. Modeling of residual stresses in laser welding. Paton Weld J. 2008;6:19-24.

7. De A, DebRoy T. Reliable calculations of heat and fluid flow during conduction mode laser welding through optimization of uncertain parameters. Weld J. 2005;84:101-12.

8. Gery D, Long H, Maropoulos P. Effects of welding speed, energy input and heat source distribution on temperature variations in butt joint welding. J Mater Process Technol. 2005;167:393-401.

9. Chang WS, Na SJ. A study on the prediction of the laser weld shape with varying heat source equations and the thermal distortion of a small structure in micro-joining. J Mater Process Technol. 2002;120:208-14.

10. Dowden JM. The mathematics of thermal modeling. USA: Taylor \& Francis Group; 2001.

11. Belhadj A, Bessrour J, Bouhafs M, Barrallier L. Experimental and theoretical cooling velocity profile inside laser welded metals using keyhole approximation and Boubaker polynomials expansion. J Therm Anal Calorim. 2009;97:911-5.

12. Abderrazaka K, Ben Salemb W, Mhiria H, Lepalecc G, Autric M. Modelling of $\mathrm{CO}_{2}$ laser welding of magnesium alloys. Opt Laser Technol. 2008;40:581-8.

13. Tsirkas SA, Papanikos $P$, Kermanidis Th. Numerical simulation of the laser welding process in butt-joint specimens. J Mater Process Technol. 2003;134:59-69.

14. Strezov V, Lucas JA, Strezov L. Computer aided thermal analysis. J Therm Anal Calorim. 2003;72:907-18.

15. Piekarska W, Kubiak M. Three-dimensional model for numerical analysis of thermal phenomena in laser-arc hybrid welding process. Int J Heat Mass Transf. 2011;54(23-24):4966-74.

16. Rai R, Kelly SM, Martukanitz RP, Debroy T. A convective heattransfer model for partial and full penetration keyhole mode laser welding of a structural steel. Metall Mater Trans A. 2008;39A: 98-112.

17. Lee SJ, Lee YK. Latent heat of martensitic transformation in a medium-carbon low-alloy steel. Scripta Mater. 2009;60:1016-9.

18. Woodard PR, Chandrasekar S, Yang HTY. Analysis of temperature and microstructure in the quenching of steel cylinders. Metall Mater Trans B. 1999;30B:815-22.

19. Bedenko DV, Kovalev OB, Krivtsun IV. Simulation of plasma dynamics in a keyhole during laser welding of metal with deep penetration. J Phys D. 2010;43:105501.

20. Beck M, Berger P, Hugel H. The effect of plasma formation on beam focusing in deep penetration welding with $\mathrm{CO}_{2}$ lasers. J Phys D. 1995;28:2430-42.

21. Semak V, Matsunawa A. The role of recoil pressure in energy balance during laser materials processing. J Phys D. 1997;30: 2541-52.

22. Michaleris P, DeBiccardi A. Prediction of welding distortion. Weld J. 1997;4:172-81.

23. Nedjar B. An enthalpy-based finite element method for nonlinear heat problems involving phase change. Comput Struct. 2002;80:9-21.

24. Piekarska W, Kubiak M, Bokota A. Numerical simulation of thermal phenomena and phase transformations in laser-arc hybrid welded joints. Arch Metall Mater. 2011;56(2):409-21.

25. Lee KJ. Characteristics of heat generation during transformation in carbon steels. Scripta Mater. 1999;40:735-42.

26. Serajzadeh S. Modelling of temperature history and phase transformations during cooling of steel. J Mater Process Technol. 2004; 146:311-7.

27. Zhang W, Wood B, DebRoy T, Elmer JW, Palmer TA. Kinetic modeling of phase transformations occurring in the HAZ of C-Mn steel welds based on direct observations. Acta Mater. 2003;51(12):3333-49.

28. Piekarska W. Numerical analysis of thermomechanical phenomena during laser welding process. The temperature fields, phase transformations and stresses. Monograph series no. 135. Czestochowa; 2007.

29. Orlich J, Pietrzeniuk HJ. Atlas zur Wärmebehandlung der Stähle. vol. 3. Dusseldorf; 1973. 